\title{
SOBRE LA POSIBLE "SUPERACIÓN" DE LA EPISTEMOLOGÍA *
}

\author{
María Elena Candioti de De Zan
}

UNER

Con su característica inclinación a romper con los "absolutos" o con toda forma de posición esencialista, Richard Rorty sostiene que no hay cuestiones filosóficas que puedan vincularse a una supuesta "naturaleza" humana. Las concepciones filosóficas no son respuestas diversas a un conjunto estable de problemas que persiste en su historicidad. Las preguntas mismas se presentan en su radical contingencia ${ }^{1}$. Sin duda las preguntas filosóficas están signadas por la contingencia; pero tenemos que admitir, que si bien no son esenciales, son al menos recurrentes. La recurrencia no implica, en este caso, identidad ni persistencia en los mismos conceptos, sino resignificación en nuevos contextos. Son estos desplazamientos los que queremos ahora explorar en relación con la problemática centrada en el conocimiento y algunas ideas vinculadas a ella -tales como la de "verdad", "objetividad", "realidad"-, especialmente porque en este siglo y medio que nos precede han sido alternativamente sacralizadas o cuestionadas, sostenidas con tenacidad dogmática y clausurante, o duramente "desenmascaradas".

Nuestra reflexión se desarrolla a partir de lo que Ch. Taylor llama "derrocamiento" de la moderna epistemología standar ${ }^{2}$; derrocamiento que no sólo pone en juego el proyecto "fundacionalista" de esta disciplina, sino también una idea de conocimiento. La Epistemología, en otros tiempos el orgullo de la filosofía moderna, parece estar enferma hoy en día -sostiene con expresiones que recuerdan la consideración de Kant respecto a la Metafísica..

El proyecto moderno mostró como finalidad prioritaria de la filosofía la de legitimar desde las bases un conocimiento "cierto", a través de un análisis previo que establezca el método y los criterios adecuados. Se adjudicó así una función de delimitación y fundamentación, en cuanto puede comprender la naturaleza del saber humano y, por lo tanto, juzgar y evaluar a partir de allí todo otro orden cultural. La impronta cartesiana de esta posición es notoria: lo que se busca

\footnotetext{
* Ponencia presentada a las IX Jornadas de Filosofía del NOA. Universidad Nacional de Catamarca, septiembre de 2000.

${ }^{1}$ Rorty, R., "La contingencia de los problemas filosóficos", en Verdad y Progreso. Barcelona, Paidós, 2000 , p. 304.

${ }^{2}$ Taylor, Ch., "La superación de la Epistemologia", en Argumentos filosóficos. Ensayos sobre el conocimiento, el lenguaje y la modernidad, Barcelona, Paidós, 1997, p. 34.
} 
es un punto de vista sólido y neutral, un punto arquimédico que pueda sostener el edificio del saber. La idea de una disciplina que sirva de "base" a las pretensiones del conocimiento se consolida en el siglo XIX cuando, por obra de los neokantianos, se define en su "especialización", es decir, se determina como orden autónomo con objetivos propios, independientes de la metafísica, que debe garantizar el conocimiento de las distintas disciplinas empíricas. El perfil que se le asigna, apartándola de las "especulaciones" y teorizaciones "vagas", expresa el espíritu cientista de la época y hace coincidir al neokantismo y al positivismo en objetivos comunes. La misma fidelidad al proyecto fundacionista puede detectarse en las líneas neopositivistas, pese al desplazamiento desde el contenido mental a la representación lingüística; la centralización en el lenguaje no varía en este caso el intento de lograr un marco de referencia permanente y neutral. Con este movimiento queda consolidada la epistemología como el saber que organiza y legitima el conocimiento, garantizando su validez. Tal posición de privilegio la convertía (y en algunos ámbitos la sigue convirtiendo) en la palabra definitiva; vigila la objetividad del conocimiento y certifica la "corrección" de las inferencias que permiten la aplicación de la "teoría" al orden de la acción.

Este ordenamiento está hoy alterado, y las rupturas no son recientes. Podemos decir que las "heridas" infligidas a la idea de conocimiento objetivo tienen más de un siglo; sin embargo, esto no ha sido un obstáculo que haya desanimado la pretensión de un saber capaz de demarcar y reglamentar. Las heridas se sometieron a una terapia intensiva, consistente en calificar de ideológico o pseudocientífico todo intento que se viese como una posible transgresión respecto a las pautas de objetividad. Esta terapia se valió incluso de algunas amputaciones, como la operada por Popper en una "epistemología sin sujeto cognoscente" 3 .

Entre heridas y amputaciones la clásica epistemología ha terminado por debilitarse, hasta tal punto que nos encontramos hoy ante la pregunta si tiene todavía sentido plantearse una reflexión epistemológica. Trataremos de ver si este debilitamiento y hasta "enfermedad" es incurable, si el campo epistemológico está viciado internamente y por tanto lo único sensato es denunciar sus errores y desarmar sus estructuras, o si lo que en realidad se está necesitando es una nueva configuración, a partir de la flexibilización de sus conceptos centrales.

En la Filosofia y el espejo de la naturaleza (1979) Rorty ha desnudado su pretensión de saber rector, mostrando sus supuestos. En la medida en que

\footnotetext{
${ }^{3}$ Popper, K., "Epistemología sin sujeto cognoscente", en Conocimiento objetivo, Madrid, Tecnós, 1982 , pp. 106 a 120
} 
éstos resultan insostenibles -incluso a la luz de los propios desarrollos de las ciencias- se siente autorizado para dar también el golpe de gracia a la Epistemología. Con esto se suma a las voces que desde la filosofía continental, siguiendo el camino abierto por Nietzsche y luego por Heidegger, desplazan las preocupaciones filosóficas a otros terrenos y ven en la búsqueda de "objetividad" una renuncia a un auténtico pensar.

Efectivamente, el proyecto epistemológico moderno y sus derivaciones neopositivistas han mostrado su fracaso y agotamiento. Sus prescripciones no han sido reconocidas por las ciencias que pretendía fundar; más bien parece que marcha por detrás de ellas, y que opera sus cambios una vez que la batalla ya se ha librado en los terrenos específicos de la ciencia. En este sentido, sería un programa "regresivo". Además del agotamiento de sus tecnicismos, el giro lingüístico en sus sucesivas etapas ha sido definitorio no solamente para mostrar las dificultades del proyecto moderno, sino para alejar la reflexión filosófica de este terreno, hasta el punto de hablar de una superación de la epistemología, como lo hace Taylor.

Nos queda la sensación de que esta clausura es demasiado apresurada y violenta. ¿No puede pensarse la problemática epistemológica asumiendo la crítica a los supuestos que la condicionaron, operando los necesarios desplazamientos respecto a los paradigmas clásicos, y admitiendo que su mirada no es la del omnisciente "Ojo de Dios"? Creemos que las denuncias a las pretensiones de la moderna filosofía del conocimiento de constituirse en un saber prescriptivo, fundante y apriori, son acertadas; pero renunciar a la pretensión de fundamentación y a las ideas involucradas en esta pretensión, no implica necesariamente renunciar a la epistemología.

¿Qué significa su "superación"? ¿Intentar una forma más ajustada? ¿Abandonarla? Hay quienes intentaron rescatarla recortando sus aspiraciones, y ubicándola en un plano más limitado y al mismo tiempo más riguroso. Es esta la idea de una Epistemología "naturalizada", tal como Quine ha propuesto ${ }^{4}$; se trata de olvidar su posición de privilegio, e intentar un tratamiento "científico" de la misma. En la misma dirección pueden considerarse los desarrollos de la Ciencia Cognitiva y su particular manera de "naturalizar" la mente. En este caso, y más allá de las múltiples observaciones y críticas que podríamos plantear a estas líneas, cabe preguntarse si hay aquí una "superación" de la epistemología, o si más bien se trata de una derivación que responde a un ideal cognoscitivo restric-

\footnotetext{
+ Quine. W.V., "Epistemology Naturalized”, en Ontological Relativity and Other Essays. N. York, 19996, pp. 69-90
} 
tivo, una especie de producto de segunda generación, resultante de un proyecto (en este caso efectivo) de conocimiento objetivo que reitera en una nueva versión un ideal de conocimiento científico.

La posible superación parece más bien estar indicando una reconsideración de las ideas que están en su base y condicionaron su trayecto histórico. El proyecto fundacionista necesitó un punto de partida incuestionable; recurrió a experiencias privilegiadas e incorregibles, dadas en la inmediatez de la conciencia. El paso necesario para ello fue una reducción a la inmanencia que ha dejado su sello en la filosofía posterior. Las consecuencias están a la vista: por un lado la concepción del conocimiento como representación exacta, lo cual indica que un contenido mental (interno) debe corresponder a una realidad externa, por otro, un dualismo persistente. La filosofía de la conciencia, asentada sobre la relación sujeto-objeto, y el ideal de saber autónomo, constituyen el marco organizador.

Para justificar su ruptura Taylor aduce que la tradición moderna está viciada por la idea de "representación" y por el mecanicismo, y éste implica una intrínseca afinidad con el ideal de certeza autorreflexiva y autodada; a su vez este ideal responde a una concepción puntual del yo ligada a una racionalidad instrumental, y a una concepción atomista (individualista) de la sociedad, que tiene implicaciones morales. Entendiendo que se hace necesaria una perspectiva moral y filosófica diferente, sugiere otro camino para el análisis del conocimiento. Este camino remite a una experiencia más originaria que no resulta inteligible bajo la interpretación epistemológica, ni en su versión empirista ni en la racionalista; experiencia de la cual habrían dado cuenta pensadores como Wittgenstein, Heidegger o Merleau Ponty, mostrando que hay una relación intencional primaria que es del orden de la práctica y se relaciona a determinadas formas de vida compartidas con otros. Esta experiencia que se muestra en una especie de apelación a la intuición, es caracterizada como nuestro "conocimiento de agente." Los desplazamientos mencionados lo conducen a afirmar que: "El fundacionismo queda minado porque no se puede continuar cavando por debajo de nuestras representaciones básicas. Lo que descubrimos y que subyace a nuestras representaciones del mundo...ya no es representación, sino una cierta captación del mundo que tenemos en tanto agentes en él. Lo cual muestra -concluye- que toda la interpretación epistemológica del conocimiento es errónea, ya que éste no sólo consiste en imágenes internas de una realidad externa, sino que se basa en algo bastante distinto",

\footnotetext{
${ }^{5}$ Taylor, Ch.: op. cit., p. 32
} 
Lo que se presentó como el movimiento esencial de la epistemología, el distinguir estados del sujeto de rasgos del mundo exterior, no puede realizarse. No puede trazarse una línea definida entre mi imagen de un objeto y el objeto, no puede definirse ni precisarse mi relación con el objeto, y el objeto mismo. No podemos seguir manteniendo la idea de un sujeto desvinculado y "transparente", de un yo puntual y de conocimiento autónomo. La filosofía del lenguaje de los dos últimos siglos no solamente indica una mirada diferente sobre el rol que éste cumple en la configuración del pensamiento, sino que, desde una perspectiva pragmática, pone en primer plano la idea de que estos procesos no son puramente individuales, sino que se dan en una comunidad de habla. Pero de aquí se infiere sólo el derrocamiento de aquellas formas de epistemología fundacionistas, y de las que aún despegándose de esta pretensión (como la de Quine), siguen aferrados a una idea de conocimiento, privilegiando una forma de lenguaje (el de la ciencia). Los argumentos en oposición al mecanicismo, a la idea de sujeto desvinculado y puntual, y al individualismo, son atendibles y adecuados, pero no muestran más que la imposibilidad de mantener una epistemología edificada sobre la idea de representación y sobre una idea de conocimiento desprendida del lenguaje y de la acción.

Si la epistemología tiene que identificarse con ese proyecto, podemos estar de acuerdo con Taylor (y también con Rorty). En lo que no estamos de acuerdo es en dejar como irrelevante o restrictiva la problemática del conocimiento. Lo que ha quebrado a la epistemología es ese fundacionismo que requiere una especie de "espejamiento" de la realidad; pero puede darse otra forma de reflexión epistemológica que asuma la multiplicidad de sentidos del conocimiento; que no se funde en el primado de una filosofía de la conciencia, en el dualismo, y en una idea de conocimiento reductiva. Las dificultades de una epistemología dependiente de la idea de representación se han hecho ya manifiestas: desde el problema del "puente" hasta las ontologías que privilegian un único lenguaje. No han sido más afortunadas las alternativas que postulan un "antirepresentacionismo" como es el caso del consensualismo rortyano; en definitiva sigue siendo tributario del mismo esquema. La idea de representación como "copia" de la realidad ha caído por su propio peso. Nuestra descripción del mundo está modelada por nuestras "elecciones" conceptuales y como en toda elección hay valoraciones e intereses, pero admitir esto no desemboca necesariamente en la trivialidad de un convencionalismo semántico.

La suerte de la epistemología está ligada a la idea de conocimiento. ¿Se trata entonces de desentrañar su naturaleza? O es que no podemos hablar de una "naturaleza" del conocimiento? Tal vez allí esté la clave; el intento de definirlo de manera unívoca puede ser la fuente de donde derivan los progresivos estrechamientos de la epistemología tradicional. Hay quienes (como Kant y poste- 
riormente Quine), han sostenido que solo la imagen científica del mundo puede ser considerada "conocimiento"; sin embargo hay múltiples lenguajes y múltiples imágenes del mundo. Ninguno de ellos es privilegiado 6 . La palabra "conocer" no tiene un significado que la circunda como un "aura" que la acompaña en todos los contextos en que se aplica.- señala Putnam-. Pretender una noción unívoca de conocimiento es una ilusión. "Nadie puede afirmar cuáles son los criterios que permitirán determinar en el futuro cuáles serán los usos lícitos o racionales, y cuáles los usos ilícitos o irracionales, porque esto no es algo que se pueda observar de una vez y para siempre. Los seres humanos son criaturas que se sorprenden a sí mismas: de la misma forma en que estamos constantemente creando nuevos juegos de lenguaje y continuaremos haciéndolo, así también estamos siempre extendiendo y modificando el significado del término "conocer"?.

¿Tiene entonces la epistemología que ir por detrás de la idea de conocimiento? ¿Es su función un análisis a posteriori que acompañaría el movimiento de estos diversos juegos, para interpretarlos en su total contingencia y diversidad? Tampoco esto tendría mucho sentido. Si bien hemos afirmado que hay múltiples formas de entender el conocimiento, no todas son válidas. Una cosa es el pluralismo y otra, el escepticismo epistemológico; y desde aquí vemos que hay aún un núcleo de problemas que perfilan nuevas direcciones para una epistemología que considere el conocimiento a partir de la experiencia comprensiva del mundo, es decir, a partir de sus nexos con el lenguaje y la acción. La consideración de la trama simbólica que condiciona nuestro acceso a lo real es ya una cuestión instalada, especialmente en la epistemología de las ciencias sociales, pero hay aún deudas pendientes, tales como asumir el "holismo" de la interpretación sin renunciar al conocimiento de la realidad, articular la negación de experiencias privilegiadas e incorregibles, con la posibilidad de discernimiento. Esta posibilidad no requiere el regreso a experiencias fundantes, sino capacidad para formar conceptos compartidos, y encontrar el modo de sostenerlos como válidos.

La racionalidad tiene que ser pensada, en este caso, no como racionalidad criterial, sino como una capacidad más rica; no como una función aislada, sino como un amplio espectro de aptitudes que nos permiten, entre otras cosas, determinar cuáles juegos de lenguaje son mejores o peores"8. Puede pensarse a partir de aquí una reflexión epistemológica que no tenga como eje la determinación de criterios, e incluya entre sus preguntas el modo en que "se aprende cuáles

\footnotetext{
${ }^{6}$ Putna, $\mathrm{H}$. "Solamente existe el lenguaje que nosotros, los seres hablantes, hemos inventado para nuestros diversificados puntos de vista". EL pragmatismo. Un debate abierto, Barcelona, Gedisa, 1999 p. 49

${ }^{7}$ Ibid .pp. 52-53

${ }^{8}$ Ibid., p. 55
} 
son los juicios correctos"9. Quizás así pueda superarse tanto el justificacionismo que recurre a la garantía del "espejo", como el contextualismo. La superación indicaría en este caso el desplazamiento respecto al modelo clásico, pero también el rechazo de las consecuencias, a nuestro juicio negativas, de su destrucción..

\title{
Resumen
}

Se analiza la situación actual de la epistemología y aquellas críticas -tales como las de Rorty y Taylor- que indican la necesidad de su superación. El trabajo se propone mostrar que el proyecto fundacionista y las ideas de representación exacta, de experiencia elemental e incorregibilidad -que desde la modernidad condicionaron la epistemología- son insostenibles. Sin embargo, puede pensarse una forma nueva de reflexión filosófica que considere la trama conocimiento / lenguaje/ acción. Esta nueva perspectiva implica atender a los múltiples juegos de lenguaje en los que puede darse el conocimiento, y configurar el campo epistemológico desde otros interrogantes.

\begin{abstract}
The aim of this work is to analyze the current situation of epistemology, and those critics, such as those presented by Rorty and Taylor, that indicate the necessity of overcoming. It is intended to show that the foundational project and ideas of exact representation, elementary experience and incorrigibility, which from modernity conditioned epistemology, are untenable. However, a new form of philosophical reflection that considers the plot knowledge / language / action, can be thought. This new perspective implicates to attend to the multiples games of language in which knowledge can be taken configurating the epistemological field from other interrogations.
\end{abstract}

\footnotetext{
${ }^{9}$ Wittgenstein sostiene que lo que se aprenden son los juicios correctos, no reglas de cálculo. Investigaciones Filosóficas., II, XI.
} 